\title{
The research of configuration for stability control device in smart substation
}

\author{
Ye $\mathrm{He}^{1}$, Binjiang $\mathrm{Hu}^{2,3,4, *}$, Dongxu Chang ${ }^{2,3,4}$, Jie Zhang ${ }^{2,3,4}$, Lingfang $\mathrm{Li}^{1}$, and Yixuan $\mathrm{Chen}^{1}$ \\ ${ }^{1}$ Power Planning and Research Center Yunnan Power Grid Co., Ltd. Kunming, China \\ ${ }^{2}$ State Key Laboratory of HVDC, Electric Power Research Institute, China Southern Power Grid, \\ Guangzhou, China \\ ${ }^{3}$ Guangdong Provincial Key Laboratory of Intelligent Operation and Control for New Energy Power \\ System, Guangzhou, China \\ ${ }^{4}$ CSG Key Laboratory for Power System Simulation, Electric Power Research Institute, China \\ Southern Power Grid, Guangzhou, China
}

\begin{abstract}
A unified specification to design and operate the stability control device in smart substation has not been formed yet, which has greatly affected the promotion and application of stability control device in smart substation. Thus, referring to the technical specifications of protection device and combining to the specificity of stability control device, a full and detailed configuration scheme is proposed to meet the requirement, including the device configuration principle, the access configuration of SV and GOOSE for variable primary connection types, the virtual terminal and soft switch. This solution is beneficial to standardize the R\&D of stability control device in smart substation, and to facilitate on-site debugging, operation and maintenance.
\end{abstract}

\section{Introduction}

Smart substations have entered the stage of comprehensive construction in China. Smart substations use digital technology to digitize the entire process of substation information collection, transmission, processing, and output. They consist of intelligent equipment, communication network, unified model and communication protocol, automated operation management, etc. [1-3].

Security and stability control device are the second and third lines of defense, which are necessary to maintain the safe, stable and reliable operation of the power system. They are widely used in many conventional substations in China [4], but not the same case in smart substations. The application is still in its infancy. Different from the relay protection device, the smart substation stability control device needs to access SV(Sampled Values) sampling values of different voltage levels from multiple bays, need to receive multiple circuit breaker position signals, protection trip signals, and send GOOSE(Generic Object Oriented Substation Events) signals such as trip commands [3]. Therefore, the data to be processed by the smart substation stability control device is much larger than the relay protection equipment at a certain bay. On the one hand, the optical fiber communication in smart

* Corresponding author: hubj@csg.cn 
substation greatly reduces the cables and secondary circuits connected by the stability control device, reduces the complexity, and can easily achieve data sharing through Ethernet, and realize information exchange between the substation equipment; on the other hand, because the amount of data exchange between the stability control device is large and the process layer is complicated, the workload of device development, design and on-site debugging and maintenance is increased.

Therefore, it is necessary to design a complete set of design specifications for the smart substation stability control device. With the help of mature " virtual terminals " technology and substation configuration description language (SCL) tool [1-2], the standard access to smart substation stability control device is guaranteed.

This article refers to the technical specifications of the stability control device [5] and the smart substation relay protection specification [6]. First, the configuration principle and access volume of the stability control device of the smart substation are clarified, and under the guidance of this principle, various SV sampling value of process-layer in primary connection types and GOOSE signal access scheme are sorted out and standardized, and the standard virtual terminals and soft switch configuration scheme of each bay unit is formed. The design scheme has been widely used in the design of the stability control device of the domestic smart substation, which greatly reduces the site commissioning workload and the difficulty of engineering maintenance, and enhances the reliability of the device.

\section{Device configuration principles}

Consistent with conventional substations, the stability control device for smart substations with voltage levels above $220 \mathrm{kV}$ should be double configuration. For smart substations below $110 \mathrm{kV}$, the stability control device should be configured with a single set in principle, and some important substations below $110 \mathrm{kV}$ should still be double configuration. The two sets of double configuration devices can be used in parallel operation mode or main assistant operation mode according to the actual situation [6].

Stability control devices are generally distributed, and there is basically no strong coupling relationship between the bays. Therefore, their design is generally based on the bay, which is called "unit" [4]. A unit can represent a circuit, a main transformer, a generator, a bus, etc. The design of the smart substation stability control device also uses the input/output signals of the bay as the basic unit, including SV sampling, GOOSE input and output signals, etc., forming a basic configuration module of a unit. The design of the device is a combination of multiple unit configurations.

According to needs, one unit of the stability control device needs SV sampling mainly including the three-phase voltage and three-phase current of the bay. The GOOSE signals to be received mainly include the following three categories: (1) Circuit breaker position signal; (2) Trip signal sent by the protection device; (3) Primary equipment operation information (such as DC pole control, reactor, Capacitor, etc.) sent by other IED equipment. The GOOSE trip signal that needs to be output is mainly to trip the line of local station (including the load line of lower voltage level of local station, etc.), and other control information is sent to the remote substation through the communication channel.

The voltage (current) SV sampling value of the dual stabilization control device shall be taken from the independent merging unit (MU). Each device shall support SV sampling input with multiple bays and multiple voltage levels in the station. According to the practice of domestic smart substation construction, the point-to-point sampling value transmission method of the IEC61850-9-2 protocol is generally adopted between the stability control device and each bay merging unit MU (hereinafter referred to as "direct sampling"); some load lines below $110 \mathrm{kV}$ can use the network sampling value transmission method (hereinafter referred to as "network sampling"). 
The circuit breaker position and trip GOOSE signal transmission of the dual stability control device should also correspond to the independent intelligent terminals of each bay, generally adopting point-to-point acquisition and trip mode. The protection trip GOOSE signal and other IED operation information required by the stability control device can be transmitted via GOOSE network. The dual stabilization control device GOOSE signal reception adopts the "dual single network" mode, that is, the two sets of devices receive GOOSE signals from different source networks respectively, which improves independence and reduces the risk of generating GOOSE network storms [2].

The single set of stability control devices are generally used for voltage levels below $110 \mathrm{kV}$. The SV sampling and goose trip exits can use "direct sampling and direct trip" or network transmission methods according to the actual project.

\section{Device configuration schema}

With reference to the Testing Specification of Security and Stability Control System for Power System [6], the SV sampling value and GOOSE signal of the stability control device need to be standardized according to the electric main bus bar type of the substation.

\subsection{3/2 Connection type scheme}

The $3 / 2$ connection type stability control device should be double distributed configuration, each device should support the SV sampling input of multiple units. In order to be compatible with breaker in middle current SV sampling and circuit breaker position signals, the design is based on the scheme that the complete string is a basic module access device. The input signal configuration of one unit (such as line 1) is shown in Table I.

Table 1. SV/GOOSE configuration table of $3 / 2$ connection type.

\begin{tabular}{|l|l|l|}
\hline \multicolumn{1}{|c|}{ SV and GOOSE } & \multicolumn{1}{|c|}{ Source IED/Destination IED } & \multicolumn{1}{|c|}{ Sampling Method } \\
\hline Line voltage SV (1) & Line voltage merging unit & Direct sampling \\
\hline Side breaker current SV(2) & $\begin{array}{l}\text { Side breaker current merging } \\
\text { unit }\end{array}$ & Direct sampling \\
\hline Breaker in middle current SV(3) & $\begin{array}{l}\text { Breaker in middle current } \\
\text { merging unit }\end{array}$ & Direct sampling \\
\hline Protection trip signal GOOSE(4) & Protection device & Network sampling \\
\hline $\begin{array}{l}\text { Side breaker position signal } \\
\text { GOOSE(5) }\end{array}$ & Side breaker IED & Direct sampling \\
\hline $\begin{array}{l}\text { Breaker in middle position signal } \\
\text { GOOSE6 }\end{array}$ & Breaker in middle IED & Direct sampling \\
\hline
\end{tabular}

Figure 1 graphically shows the communication connection between the $3 / 2$ connection type stability control device and the IED equipment in the bay. 


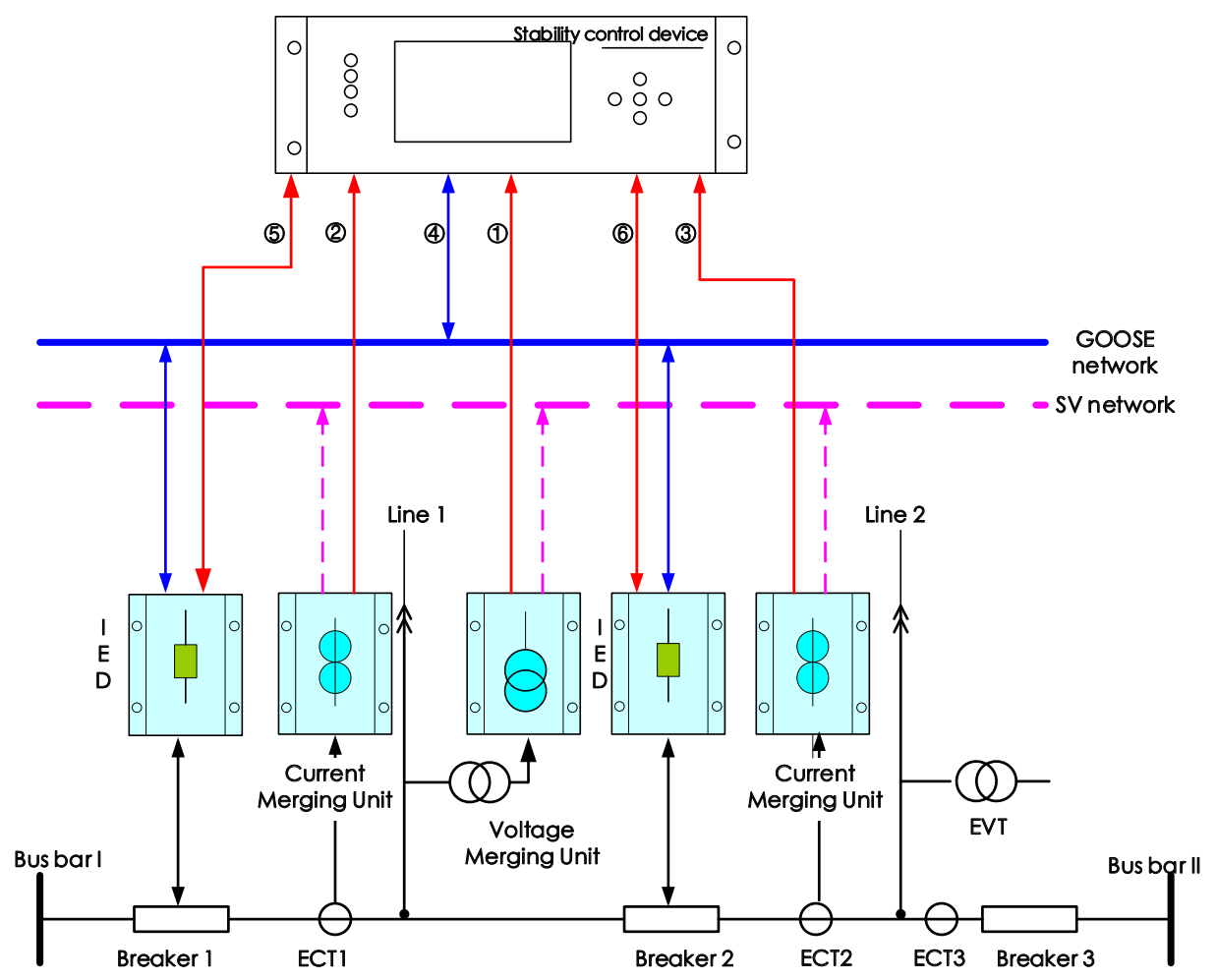

Fig. 1. Typical configuration of $3 / 2$ connection type.

For the $3 / 2$ connection type, the two bays of the same string share an input of the breaker in middle current MU. Therefore, the polarity of breaker in middle current relative to the two side breaker currents of the same string should be configurable. In the sample area, two bays in the same string share a GOOSE input signal of the intelligent terminal of the breaker in middle, and the GOOSE output directly acts on the exit of the side breaker and breaker in middle of the intelligent terminal. Both devices need to design corresponding configurable schemes.

\subsection{Double bus bar connection type scheme}

In the double bus bar connection type, the device SV sampling also adopts the point-to-point sampling method. In order to avoid the complex voltage switching of the bus voltage by the stability control device, the switched bus voltage and bay current input by the bay merging unit can be accessed, such as Table II. 
Table 2. SV/GOOSE configuration table 2 of double bus bar connection type .

\begin{tabular}{|c|c|c|}
\hline SV and GOOSE & Source IED/Destination IED & Sampling Method \\
\hline Line current SV (1) & Line merging unit & Direct sampling \\
\hline Bus bar voltage SV(2) & Source IED/Destination IED & Direct sampling \\
\hline $\begin{array}{c}\text { Breaker position } \\
\text { signal GOOSE (3 }\end{array}$ & Line breaker IED & Direct trip \\
\hline $\begin{array}{c}\text { Trip local bay GOOSE } \\
\text { signal (3 }\end{array}$ & Line breaker IED & Network sampling \\
\hline $\begin{array}{c}\text { Protection trip signal } \\
\text { GOOSE (4) }\end{array}$ & Protection device & Sampling Method \\
\hline SV and GOOSE & Source IED/Destination IED & \\
\hline
\end{tabular}

The communication connection between the double bus bar connection type stability control device and the IED equipment of the bay layer is shown in Figure 2.

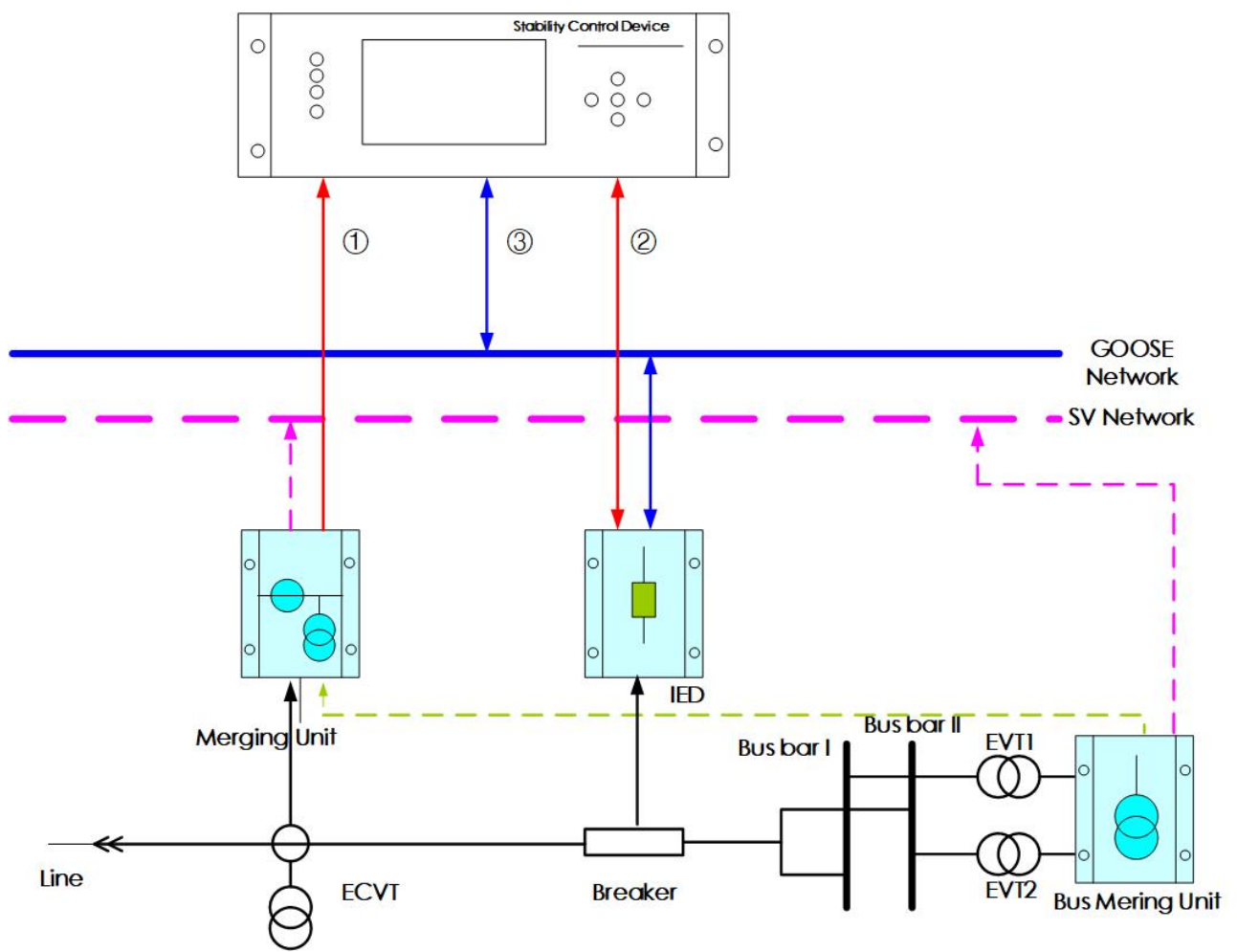

Fig. 2. Typical configuration 1 of double bus bar connection type.

For some stations that need to collect bus voltage for low-frequency low-voltage load shedding, to simplify configuration, the device SV sampling can directly access to the two bus bars voltages of the bus merge unit (regardless of split operation) and the current of each bay merge unit. The device software automatically switches each bay voltage according to 
the bus voltage sampling value, and its configuration and communication are shown in Table III and Figure 3.

Table 3. SV/GOOSE configuration table 2 of double bus bar connection type.

\begin{tabular}{|c|c|c|}
\hline SV and GOOSE & Source IED/Destination IED & Sampling Method \\
\hline Line current SV (1) & Line merging unit & Direct sampling \\
\hline Bus bar voltage SV(2) & Source IED/Destination IED & Direct sampling \\
\hline $\begin{array}{c}\text { Breaker position } \\
\text { signal GOOSE (3 }\end{array}$ & Line breaker IED & Direct sampling \\
\hline $\begin{array}{c}\text { Trip local bay GOOSE } \\
\text { signal (3 }\end{array}$ & Line breaker IED & Direct trip \\
\hline $\begin{array}{c}\text { Protection trip signal } \\
\text { GOOSE 4 }\end{array}$ & Protection device & Sampling Method \\
\hline SV and GOOSE & Source IED/Destination IED & \\
\hline
\end{tabular}

\subsection{Single bus bar section connection type schema}

The single bus bar section connection type is more common in substations with voltage levels below $110 \mathrm{kV}$. The stability control devices in these voltage levels generally complete the functions of load information collection and execution of load-cutting commands. Its characteristics are that the collected load bays are many and the output GOOSE trip signals are many, but no need to collect GOOSE input signal. In some applications, in order to solve the contradiction between multi-bays simultaneous access and the computing capability of the device, it may be considered to only access the single-phase voltage and single-phase current of the bay to achieve a stability control device acquisition unit to collect up to 18 simultaneously bays.

The SV sampling and trip exit of the device can be based on the actual project using "direct sampling and direct trip" or network transmission method; due to the large number of bays required to access the device, it is recommended to use the network transmission method to reduce the optical cable connection in the station. Its typical configuration scheme is shown in Figure 4. 


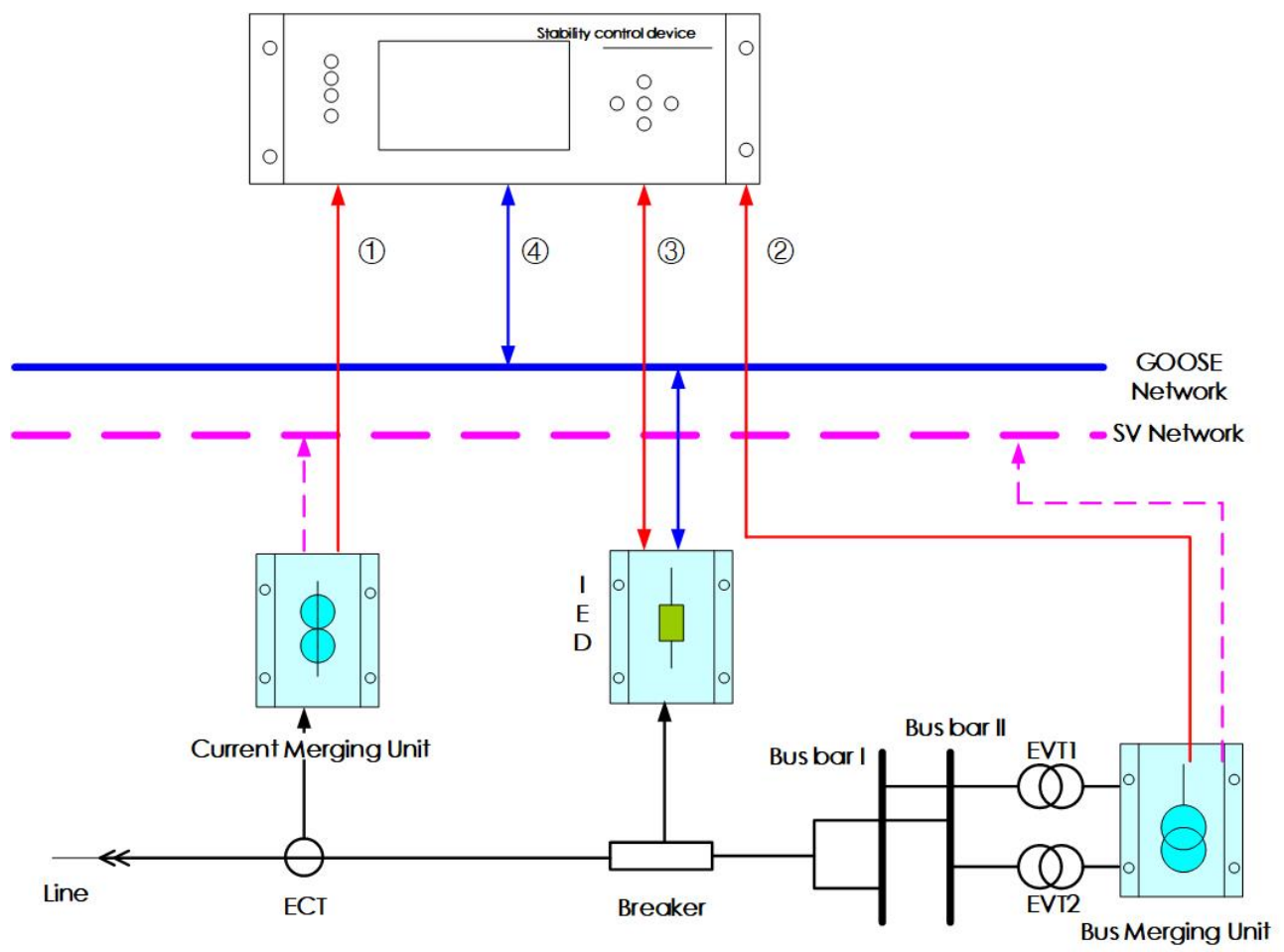

Fig. 3. Typical configuration of single bus bar section connection type.

\section{Design of virtual terminal}

Compared with the traditional substation, the signal connection between the smart substation devices is communicated through optical fiber. The terminal board such as analog input, switch input and output on the device panel are cancelled. The user can only see the communication optical fiber, the signal connection between devices becomes unintuitive. In order to solve the above problems and inherit the secondary design specifications, the concept of "virtual terminal" is introduced in the smart substation. The virtual terminal is a kind of virtual terminal, which shows the input and output of the SV sampling value and GOOSE signal of the equipment at the bay and process layers, and is the starting or ending point of the SV or GOOSE variable transmitted on the network [7]. In practical applications, the design institute draws the virtual terminal connection logic between the devices determined by the device drawings into a virtual terminal diagram of the entire smart substation. On-site debugging personnel can automatically complete the configuration process of the device's virtual terminal communication through the configuration tool SCL according to the SCD file containing the virtual terminals of the total station and the ICD file of the device.

The number of stability control devices is numerous, and it is necessary to take into account multiple voltage levels and primary connection type. Therefore, it is necessary to standardize the design of the virtual terminal of the stability control device to meet the needs of various engineering applications. The standard virtual terminals of a unit of the stability control device shall include:

SV input virtual terminal, namely bay (bus bar) three-phase voltage input virtual terminal; bay three-phase current input virtual terminal; bay three-phase current 2 input virtual terminal (compatible with switch current input in 3/2 connection type); SV sampling needs 
to provide 2 groups, separately to the device's logic plug-in and start-up plug-in, to meet the needs of the device's double sampling logic.

GOOSE input virtual terminal, namely 2 sets of split-phase trip input virtual terminals for protection; circuit breaker split-phase dual-position virtual terminal input; and spare part general GOOSE input to meet the special needs of the device.

GOOSE output virtual terminal, which provide multiple groups of GOOSE trip exits, and provide the GOOSE virtual terminal for starting wave recording to the digital fault recorder. Each group of GOOSE should be designed with corresponding soft traps. A standard virtual terminal of a bay is shown in Figure 5.

The virtual terminal standardization of the stability control device can provide a convenient modular design for the project, which is conducive to simplifying on-site debugging, operation and maintenance.

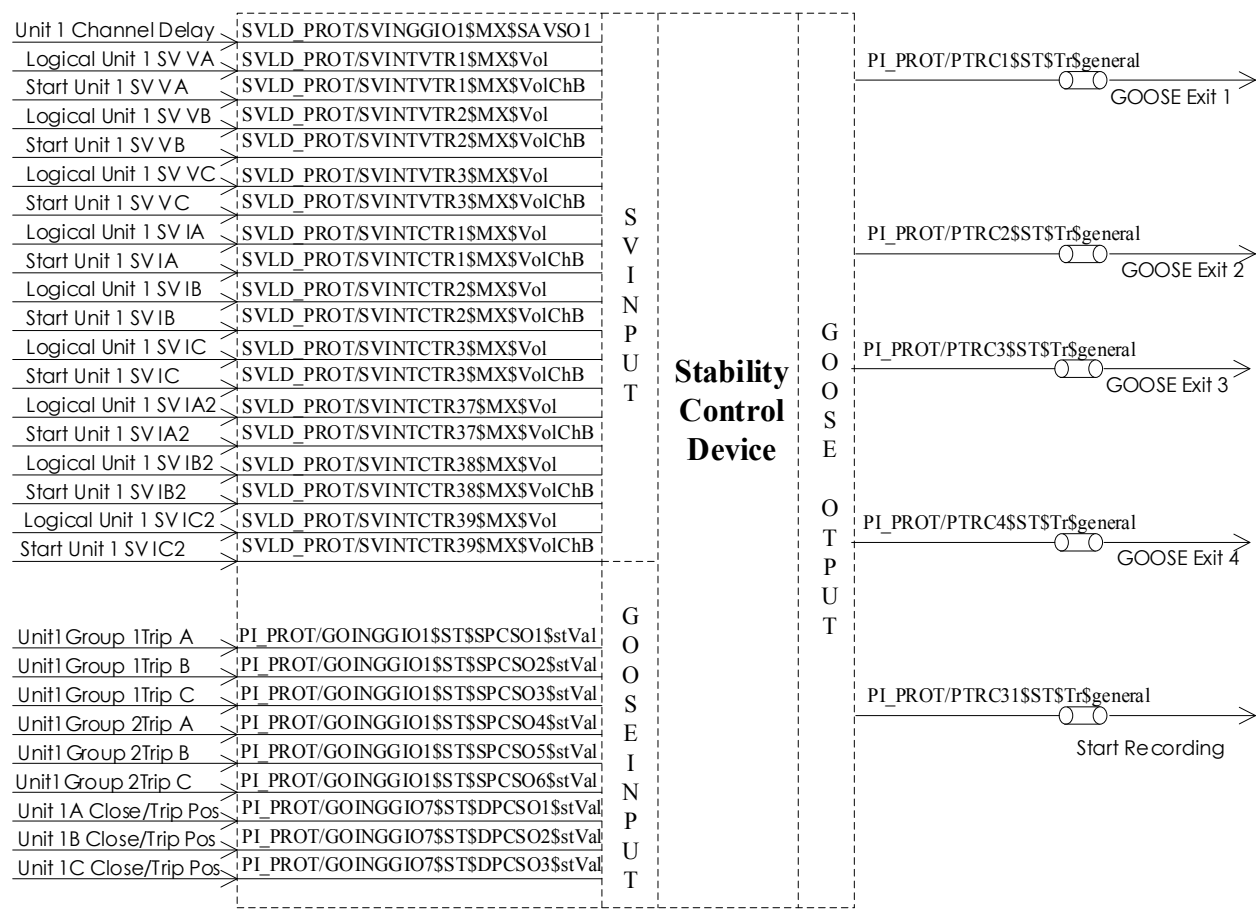

Fig. 4. The virtual terminal outlet of bay for stability control deviceThe complete virtual terminal file of the stability control device is a combination of multiple access units, which will not be listed in detail in this article.

\section{The design of soft switch}

There are many bays connecting to the stability control device, and the function of the stability control device cannot be affected when a bay or its protection equipment is overhauled; similarly, when the stability control device overhaul is finished, the stability control device also needs to adopt measures to avoid mistakenly sending GOOSE trip signal.

Smart substations have widely used soft switch instead of conventional hard switch to implement device logic function switching and secondary circuit isolation. The soft switch can be operated on the device or remotely controlled by the monitoring computer. 
The stability control device is designed for the SV input, GOOSE receiving control block and GOOSE trip of each MU (voltage, side breaker current and breaker in middle current (current 2), etc.) with corresponding soft switch, to isolate the bays and equipment under the maintenance, to control stability impact to the device function. The operation of the soft switch under various maintenance is listed in table IV.

Table 4. The soft switch operation for variable maintenance modes.

\begin{tabular}{|c|c|c|c|c|c|}
\hline $\begin{array}{c}\text { Maintenance } \\
\text { components }\end{array}$ & $\begin{array}{c}\text { voltage } \\
\text { SV input } \\
\text { soft switch }\end{array}$ & $\begin{array}{c}\text { current } \\
\text { SV input } \\
\text { soft switch }\end{array}$ & $\begin{array}{c}\text { switch } \\
\text { position } \\
\text { GOOSE } \\
\text { signal input } \\
\text { soft switch }\end{array}$ & $\begin{array}{c}\text { protection } \\
\text { tripping } \\
\text { GOOSE } \\
\text { signal input } \\
\text { soft switch }\end{array}$ & $\begin{array}{c}\text { GOOSE } \\
\text { tripping } \\
\text { output soft } \\
\text { switch }\end{array}$ \\
\hline bay maintenance & break & break & break & break & break \\
\hline switch maintenance & connect & break & break & connect & break \\
\hline $\begin{array}{c}\text { protection } \\
\text { maintenance }\end{array}$ & connect & connect & connect & break & connect \\
\hline
\end{tabular}

\section{Conclusion}

On the basis of the summary of operation experience of relay protection devices in smart substations, this paper puts forward a set of design schemes for the stability control devices of smart substations, including configuration principles, configuration schemes, design of standard virtual terminal and soft switch, etc. The configuration and implementation scheme proposed in this paper have been widely used in smart substation stability control devices of various voltage levels in the domestic power grid. In the next step, we will take the opportunity of studying the application model of the stability control device in the control layer of the smart substation to promote the modularization and standardization of the research and design of the stability control device.

\section{References}

1. Zhang C, Lu Z, Li J, et al. Protection configuration scheme and application in digital substation[J]. Electric Power Automation Equipment, 2011, 31(6): 122-125.

2. Yimin X U C S U N. A Communication Solution of Process Layer GOOSE in Digitized Substation [J]. Automation of Electric Power Systems, 2007, 19.

3. Song J, Xuan X, Zhu K, et al. Design of Security and Stability Control Device Based on IEC 61850 [J]. Automation of Electric Power Systems, 2010, 12: 016.

4. Liu Z, Lei W M, Ren Z Y, et al. Research and Application of Regional Stability Control System for Southern Beijing-Tianjin Power Grid [J]. Proceedings of the CSEE, 2007, 22.

5. Q/GDW 441-2010. Technical Specifications of Protection for Smart Substation [S]. Beijing: China Electric Power Press, 2012.

6. DL/T 1092-2008. Testing Specification of Security and Stability Control System for Power System[S]. Beijing: China Electric Power Press, 2008.

7. ZHANG Z, HU J, LIU G, et al. Engineering practice of digital substation based on peer-to-peer technology [J]. Electric Power Automation Equipment, 2009, 4. 